\title{
A Review of the Methodology, Taxonomy, and Definitions in Recent fMRI Research on Meditation
}

\author{
Maria Engström ${ }^{1,2}$ [D $\cdot$ Johan Willander ${ }^{3} \cdot$ Rozalyn Simon $^{1,2}$
}

Accepted: 15 October 2021 / Published online: 12 November 2021

(c) The Author(s) 2021

\begin{abstract}
Objectives As meditation is increasingly employed for the promotion of good health, there is a growing interest in using neuroimaging methods to investigate the neural mechanisms by which meditation acts. In the wake of this rising interest, criticism regarding the lack of clarity concerning theory, definitions, and taxonomy, as well as deficient or poorly reported methodology, has arisen. The aim of this study was to investigate trends in current neuroimaging research on meditation and to provide guidelines for future studies.

Methods We made a literature search for articles published during 2016-2019 using the search phrases "meditation" and "functional magnetic resonance imaging or fMRI". Inclusion criteria were limited to meditation studies using resting-state fMRI or such task-based fMRI examinations that were specifically targeting meditative states in healthy participants. Text analysis was performed using Nvivo 12 Mac (QSR International).

Results Twenty-eight articles were included from which we identified four different intention-based dimensions of meditation practice: The present moment, Wholesome qualities to cultivate, Unwholesome qualities to avoid, and Attitudes. Half of the studies do not make assessments of subjective experience. The results were related to networks and brain regions describing cognitive, affective, somatic, and self domains of brain function. Most studies describe meditation-related brain function in terms of "processes".

Conclusions We defined five areas of potential improvement regarding research methodology: (1) Provide clear and unambiguous definitions of constructs and practices, (2) Include measures of subjective experience, (3) Perform correct assessment of processes, (4) Combine methodologies for more substantiated conclusions, (5) Avoid the risk of overinterpretation.
\end{abstract}

Keywords Present moment $\cdot$ Buddhist ethics $\cdot$ Wholesome $\cdot$ State $\cdot$ Trait $\cdot$ First-person reports

Meditation practice, traditionally aiming for altered states of consciousness and spiritual development, is increasingly applied for the promotion of good health. Numerous scientific studies agree that meditation reduces stress (Pascoe et al., 2017), improves attention (Leyland et al., 2019), increases general well-being (Evans et al., 2018), and enhances different aspects of cognitive function (Crescentini et al., 2017). It is also well documented that meditation

Maria Engström

maria.engstrom@liu.se

1 Department of Health, Medicine and Caring Sciences, Linköping University, Linköping, Sweden

2 Center for Medical Image Science and Visualization (CMIV), Linköping University, Linköping, Sweden

3 Department of Occupational Health Science and Psychology, University of Gävle, Gävle, Sweden induces measurable changes in biological markers of the autonomous and central nervous system, including brain structure (Fox \& Cahn, 2018) and function (Fox et al., 2016; Young et al., 2018). This field of research is currently shifting from preliminary investigations to determine if meditation can induce changes in well-being and/or biological markers, towards investigating the mechanisms by which such changes are induced (Dorjee, 2016). There has therefore been an upsurge in the use of neuroimaging methods, specifically functional magnetic resonance imaging (fMRI), to study mental processes related to meditation (Van Dam et al., 2018).

Along with the increased interest in scientific studies on meditation, criticisms regarding the lack of clarity concerning theory, definitions, and taxonomy, as well as deficient or poorly reported methodology, has emerged (Davidson \& Kaszniak, 2015). We were interested in exploring the 
way meditation is researched in practice, as described by the authors themself in current neuroimaging literature. To reduce the number of articles, we narrowed our search to fMRI studies on healthy participants during rest or meditative states, published between 2016 and 2019. We were particularly interested in investigating how meditation practice is described and how measured brain function is then related back to the practice of meditation. The aim of the study was to highlight trends in current research on meditation and to provide guidelines for future studies.

\section{Methods}

We made a literature search in the Web of Science core collection for articles published during the years 2016-2019 to limit the number of articles in our study. The inclusion of articles from 2016 an onwards was motivated by the objective to use the critical work by Davidson and Kaszniak (2015), Conceptual and Methodological Issues in Research on Mindfulness and Meditation, as starting point for the discussion. In the literature search we used the search phrases "meditation" and "functional magnetic resonance imaging or fMRI". We also included articles found in citing works. We limited the search to studies investigating meditation and its general effects on brain function. Thus, inclusion criteria were studies using resting-state fMRI or such task-based fMRI examinations that were specifically targeting meditative states in healthy participants. Studies aiming to explore explicit cognitive functions such as working memory or emotional responses to external stimuli were excluded. For studies reporting both resting-state and general task-based fMRI, we accordingly report only descriptions of the resting-state part of the study. In addition, studies investigating patients with various disorders such as ADHD, mild cognitive impairment, and addiction were also excluded. Text analysis of the Introductions and Discussion sections of the reviewed articles were performed using Nvivo $12 \mathrm{Mac}$ (QSR International).

\section{Results}

The literature search resulted in 28 articles published 2016-2019. Most studies investigated brain function in relation to different forms of mindfulness meditation either in intervention programs or in the form of Vipassana meditation. Five studies investigated meditation according to different yoga traditions and two studies according to a Taoist tradition. Single studies investigated compassion meditation according to the Nyingma Tibetan Buddhist tradition, or other meditation techniques related to Transcendental Meditation or Brain Wave Vibration schools. The included studies are presented in Table 1 and more detailed descriptions of aims, hypotheses, research methods, results, and interpretations of results are found in supplementary Table S1.

In some studies, the participants were asked to do their usual meditation practice without providing further information to the reader. However, most of the studies provided explanations both on the applied meditation practice and instructions during fMRI scanning. Five papers provided word-by-word instructions (Table S1), for example: "Please pay attention to the physical sensation of your breath wherever you feel it most strongly in your body. Follow the natural and spontaneous movement of your breath, not trying to change it in any way. Simply pay attention to it. If you find that your attention has wandered to something else, gently but firmly bring it back to the physical sensation of the breath. Please keep your eyes open" (Kim et al., 2019).

Typical instructions for resting-state scans were to "stay awake," "relax," and "keep the eyes closed/open". Some authors did not disclose if or how the participants were instructed. Others give somewhat more elaborate instructions, for example: “... participants were directed to maintain fixation on a foveal crosshair. Subsequently, participants were explicitly instructed to relax, move as little as possible, and refrain from meditating or thinking of something specific during the fMRI scan" (Jang et al., 2018).

Half of the studies in the current review made no assessment of subjective experience, but 11 studies made confirmatory assessments of the experience during fMRI by post-scanning semi-structured interviews, verbal confirmation, rating scales, or questionnaires (Table S1). These confirmatory assessments aimed either to confirm if desired meditative states were achieved during fMRI or to exclude non-desired states, such as sleep or active meditation when that was not the central aim. Three of these studies also reported results from statistical analysis of subjective experience (Table S1).

Two studies correlated fMRI measures of brain function with measures of subjective experience, assessed either during the fMRI scan (Kim et al., 2019) or post-scanning (Hernandez et al., 2018). Two studies used subjective indications when participants were entering meditative states to guide fMRI data analysis (Jao et al., 2016; Modestino, 2016). In two other studies, indications of subjective experience during the entire fMRI scan were part of the study design. Scheibner et al. (2017) employed a "focused attention with thought probes" paradigm. In that study, the participants were asked in randomized intervals to indicate "breath" or "sound" when they experienced focused internal or external attention respectively, or to indicate "distracted" when they were not attentive. In the study by Ellamil et al. (2016), the participants were asked to attend to the breath and alternate between monitoring the arising of spontaneous thoughts and monitoring words that appeared on a screen. 
Table 1 Articles included in the text analysis

\begin{tabular}{|c|c|c|c|c|c|c|}
\hline Meditation & Experience & MED & $\mathrm{CON}$ & CON type & Paradigm & Reference \\
\hline Mindfulness (HEM) & Intervention & 18 & 17 & Relaxation training & Resting state & Creswell et al. (2016) \\
\hline Mindfulness $^{\mathrm{a}}$ & Intervention & 30 & 30 & $\begin{array}{l}\text { Non-contingent neurofeed- } \\
\text { back }\end{array}$ & $\begin{array}{l}\text { Mindfulness of breathing/ } \\
\text { Mind-wandering/Cogni- } \\
\text { tive task/Resting state }\end{array}$ & Kim et al. (2019) \\
\hline Mindfulness $^{\mathrm{a}}$ & Intervention & 19 & 18 & Waitlist & Resting state & Mooneyham et al. (2017) \\
\hline Mindfulness $^{\mathrm{a}}$ & Intervention & 20 & - & - & $\begin{array}{l}\text { Mindfulness of breathing } \\
\& \text { Mindfulness of sound }\end{array}$ & Scheibner et al. (2017) \\
\hline Mindfulness (MBSR) & Intervention & 16 & 18 & Relaxation training & $\begin{array}{l}\text { Mindful or relaxing body } \\
\text { scan \& Resting state }\end{array}$ & Sevinc et al. (2018) \\
\hline Mindfulness $^{\mathrm{a}}$ & Intervention & 23 & 22 & Relaxation training & Resting state & (Shao et al., 2016) \\
\hline Mindfulness (IBMT) & Intervention & 25 & - & - & Resting state & Tang et al. (2017) \\
\hline Mindfulness (HEM) & Intervention & 18 & 17 & Relaxation training & Resting state & Taren et al. (2017) \\
\hline Mindfulness (MOM) & Intervention & 13 & - & - & $\begin{array}{l}\text { Mindfulness of breathing/ } \\
\text { Body scan/Resting state }\end{array}$ & Tomasino \& Fabbro (2016) \\
\hline Mindfulness (MBSR) & Intervention & 16 & 16 & Naïve & Resting state & Xiao et al. (2019) \\
\hline Mindfulness & Intervention & 13 & - & - & Resting state & Yang et al. (2016) \\
\hline Vipassana & Long-term & 16 & 17 & Naïve & Meditation \& Resting state & Bauer et al. (2019) \\
\hline Vipassana (Theravada) & Long-term & 18 & 18 & Naïve & Resting state & $\begin{array}{l}\text { Berkovich-Ohana et al. } \\
\text { (2016) }\end{array}$ \\
\hline Vipassana (Mahasi) & Long-term & 18 & - & - & $\begin{array}{l}\text { Spontaneous thought/Word } \\
\text { definition }\end{array}$ & Ellamil et al. (2016) \\
\hline Vipassana & Long-term & 20 & 20 & Naïve & $\begin{array}{l}\text { Mindfulness of breathing } \\
\text { \& Resting state }\end{array}$ & Escrichs et al. (2019) \\
\hline Vipassana & Intermediate & 18 & - & - & $\begin{array}{l}\text { Focused attention \& Open } \\
\text { monitoring \& Resting } \\
\text { state (pre/post) }\end{array}$ & Fujino et al. (2018) \\
\hline Vipassana & Long-term & 21 & 19 & Naïve & $\begin{array}{l}\text { Cognitive self-reflection/ } \\
\text { Mindful self-awareness/ } \\
\text { Resting state }\end{array}$ & Lutz et al. (2016) \\
\hline $\begin{array}{l}\text { Secularized Shamatha, } \\
\text { Four Immeasurables, and } \\
\text { Vipassana }\end{array}$ & Intervention & 1 & & & Resting state & Sato et al. (2017) \\
\hline $\begin{array}{l}\text { Tibetan Buddhism } \\
\text { (Nyingma) }\end{array}$ & Long-term & 17 & 15 & Naïve & $\begin{array}{l}\text { Loving kindness \& Rest- } \\
\text { ing state }\end{array}$ & Engen et al. (2018) \\
\hline Kundalini Yoga $^{\mathrm{b}}$ & Long-term & 1 & - & - & Kundalini/Resting state & Modestino (2016) \\
\hline Kundalini Yoga & Intervention & 8 & & & $\begin{array}{l}\text { Mantra meditation/Low- } \\
\text { level finger-tapping }\end{array}$ & Simon et al. (2017) \\
\hline Raja Yoga & Long-term & 20 & 20 & Naïve & Resting state & Panda et al. (2016) \\
\hline Sahaya Yoga & Intervention & 12 & 30 & Waitlist & Resting state & Dodich et al. (2019) \\
\hline Sahaya Yoga & Long-term & 23 & 23 & Naïve & Meditation \& Resting state & Hernandez et al. (2018) \\
\hline Transcendental meditation & Long-term & 16 & - & - & Meditation/Resting state & Mahone et al. (2018) \\
\hline Brain Wave Vibration & Long-term & 35 & 33 & Naïve & Resting state & Jang et al. (2018) \\
\hline $\begin{array}{l}\text { Chinese Original Quiet } \\
\text { Sitting (Daoist) }\end{array}$ & Long-term & $17 / 16$ & - & - & $\begin{array}{l}\text { Mantra }^{\mathrm{c}} / \text { Open awareness } \\
\text { \& Mantra/Resting state }\end{array}$ & Liou et al. (2016) \\
\hline $\begin{array}{l}\text { Chinese Original Quiet } \\
\text { Sitting (Daoist) }\end{array}$ & Long-term & 18 & - & - & Meditation \& Resting state & Jao et al. (2016) \\
\hline
\end{tabular}

Note: Meditation experience is indicated as Intervention if participants were meditation naïve and Long-term if participants had years of meditation experience. $M E D$, number of meditators; $C O N$, number of controls; $C O N$ type, type of controls (active or naïve); HEM, health enhancement through mindfulness (based on MBSR); IBMT, integrative body-mind training; MBSR, mindfulness-based stress reduction program; $M O M$, mindfulness-oriented meditation. "\&" in Paradigms denotes separate scans, "” denotes different blocks in one scan

${ }^{\text {a }}$ Study-specific intervention

${ }^{\mathrm{b}}$ Spontaneous "Kundalini experience"

${ }^{\mathrm{c}}$ Invitation of primordial $\mathrm{Ch}$ ' $i$ (IPC)

${ }^{\mathrm{d}}$ Allow its natural workings (ANW) 


\section{Central Themes: Introductions}

Four different intention-based dimensions of meditation practice were identified as central themes in the articles of this review: (1) The present moment, (2) Wholesome qualities to cultivate, (3) Unwholesome qualities to avoid, and (4) Attitudes (Fig. 1). These dimensions refer both to experiences during meditation (state) and outcomes of meditation practice (trait).

\section{The Present Moment}

A central theme in most mindfulness meditation practices, including Vipassana, was "the present moment" related to observations of sensations, feelings, and thoughts. This was often expressed as "attention" or "awareness of the present moment", or in alternative phrases such as: "The purpose of training in ... mindfulness meditation is to develop the ability to direct (focus) and maintain attention towards the present moment" (Tomasino \& Fabbro, 2016).

The content of the present moment was often described in terms of "experience", e.g., "attention and awareness to one's present moment experience" (Creswell et al., 2016) or the meditator's "experience of the present moment" (Fujino et al., 2018). Experience in the context of mindfulness meditation was mainly related to sensory experiences, for example: “... paying attention to present moment sensory experience in each body area ..." (Sevinc et al., 2018). Lutz et al. (2016) expanded the notion of experience to include feelings and thoughts in addition to bodily sensations: "Mindfulness meditation and clinical mindfulness programs teach a non-judgmental present-moment awareness towards experiences, in particular towards sensations, feelings, and thoughts". A description of Sahaya Yoga meditation also referred to the concept of the present moment: "... the conscious mind is crystal clear, fully aware of each present moment, living in the here and now, in a momentby-moment basis" (Hernandez et al., 2018).

\section{Wholesome Qualities to Cultivate}

Most studies described the aims of meditation in terms of different wholesome or health-promoting qualities that the meditator seeks to cultivate. Here, we describe six types of such qualities mentioned in the fMRI literature on meditation.

"Attention": Attention was often described as the first step in mediation and a quality that is "intentional" and "focused". The attentional focus was most often directed towards the breath or other bodily sensations, but also to mind objects, such as thoughts: “... partici-
Fig. 1 Dimensions of meditation practice. Schematic overview of the four dimensions of meditation practice that were identified as central themes in the introductions of the included articles

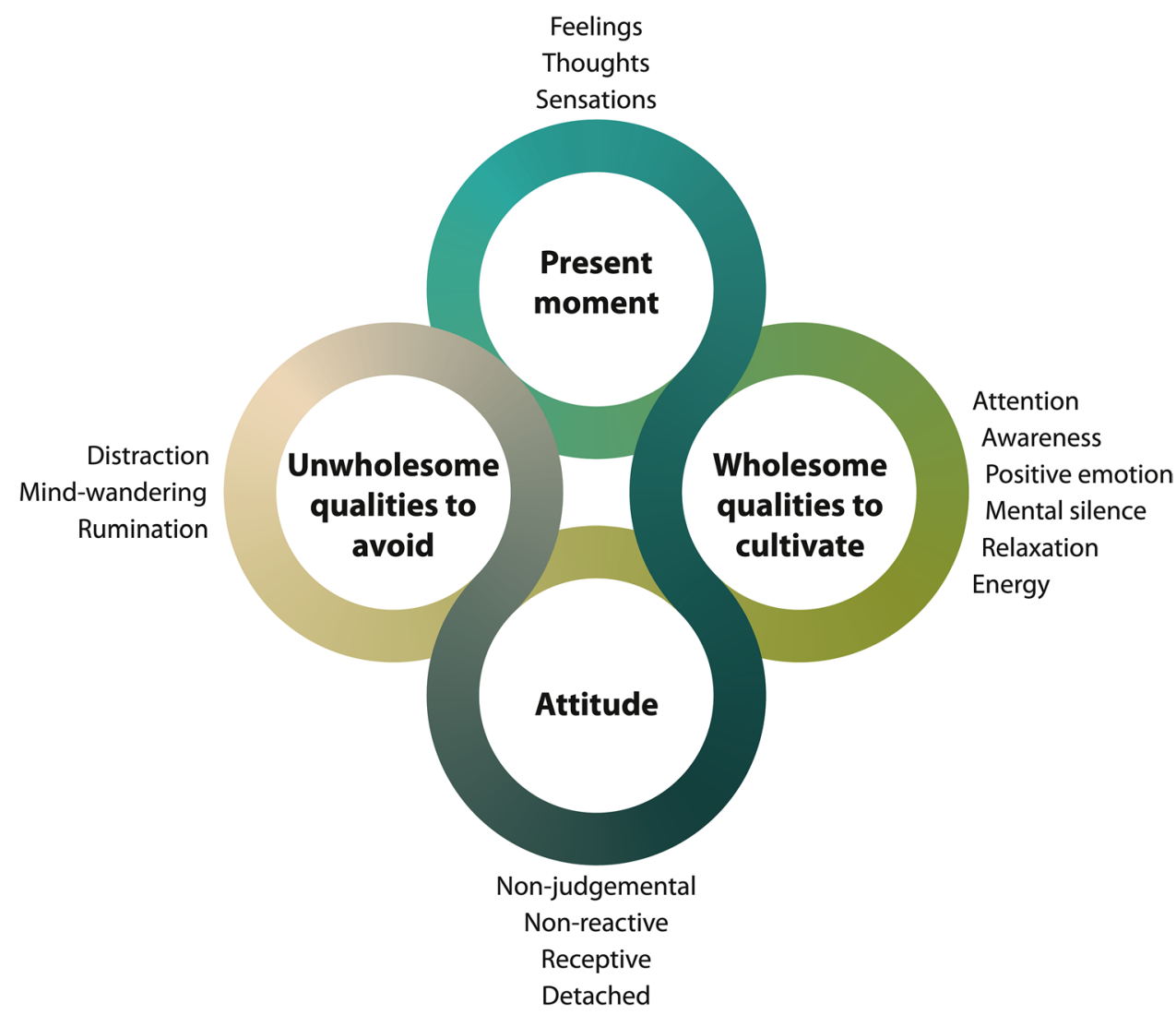


pants for example train their focus of attention on the sensation of breath entering the nostril (ānāpānasati), to different body parts (body scan), or on the observation of how thoughts, memories and fantasies appear and disappear from the mind (vipassanā)" (Tomasino \& Fabbro, 2016).

"Awareness": When the attention is focused, the more open quality of awareness can be cultivated. In the reviewed literature, we found that awareness in meditation was often described in terms of self-awareness, interoceptive awareness, emotional awareness, body/ corporeal awareness, and/or sensory awareness for example the description of integrative body-mind training (IBMT): "The method stresses no effort to control thoughts, but instead a state of restful alertness that allows a high degree of awareness of body, mind, and external instructions" (Tang et al., 2017).

Sevinc et al. (2018) stressed that "deliberate awareness" is a key feature in mindfulness practice according to the mindfulness-based stress reduction (MBSR) program as opposed to ordinary awareness of bodily sensations present during relaxation response (RR) training: "Although sensory feedback is integral to both types of body scan, only the MBSR program emphasizes deliberate awareness of these sensations, whereas the RR program focuses more on elicitation of relaxation regardless of the current bodily sensations".

\footnotetext{
"Relaxation": In this review, some studies mentioned relaxation as an aim for mediation (Hernandez et al., 2018; Jang et al., 2018; Liou et al., 2016) as for instance: "Meditation is essentially a physiological state ... that elicits physical and mental relaxation ..." (Hernandez et al., 2018). According to Tang et al. (2017), body relaxation was described as a "key component" in IBMT and "cooperation between the body and the mind is emphasized in facilitating and achieving a meditative state". However, in the MBSR program applied in the study by Sevinc et al. (2018), the participants were explicitly taught that "physical relaxation is not an aim of meditation practice".

"Wholesome emotion": Engen et al. (2018) investigated mettā meditation that explicitly aims to cultivate wholesome emotions in the form of loving kindness and compassion: "Training of loving-kindness meditation involves the active generation of feelings of warmth, love, kindness, and prosocial motivation for others; confronted with the suffering of others, lovingkindness may furthermore become compassion, associated with a wish to alleviate the suffering".
}

The aim of the Brain Wave Vibration technique was described to "induce positive mind" (Jang et al., 2018). Many other studies described wholesome emotion as a consequence of meditation training by, for example, explaining that mediation enhances "psychological balance and emotional stability" (Hernandez et al., 2018) and produces "positive physical and psychological health effects, including increased stress resilience and greater executive control" (Taren et al., 2017). Shao et al. (2016) started their introduction by stating: "Accumulating evidence indicates that meditation facilitates affective regulation, enhances positive affect and reduces negative affect states".

"Energy": Some of the non-mindfulness traditions in the present review described the aims of meditation in terms of energy. For example, mental movements between high and low "energy levels" were described as objectives in Taoist meditation, which was claimed to have health benefits (Liou et al., 2016). Experience during Kundalini Yoga meditation was described as a "sensation of energy moving along one's spine" leading to an "ecstatic state", a "pathway to spiritual enlightenment" with presumed health benefits (Modestino, 2016). Brain Wave Vibration meditation was associated with an "increased awareness of the movement of energy within the body. It aims to relax the body and induce positive mind" (Jang et al., 2018). "Mental silence": In some studies, the goal of meditation was to obtain a state of mental silence, which, for example, is described as "thoughtless awareness" (Hernandez et al., 2018), "free from unnecessary mental activity" (Dodich et al., 2019), experience of "inner silence" (Mahone et al., 2018), ceasing or slowing of the "mind's internal dialog" (Panda et al., 2016), or quieting of "the thinking mind" (Jang et al., 2018).

\section{Unwholesome Qualities to Avoid}

Along with wholesome qualities to cultivate during meditation, there were also unwholesome qualities to avoid or diminish. Here, we describe three common unwholesome qualities mentioned in the reviewed literature.

"Mind-wandering": The motivation to cultivate wholesome qualities were mostly to reduce unwholesome qualities, which often were described in terms of mind-wandering and related terms such as "stimulusindependent thought" (Ellamil et al., 2016), "random thinking processes" (Hernandez et al., 2018), or: "Mind-wandering is here defined as off-task thinking such as memory retrieval, planning for the future, or judging the present" (Scheibner et al., 2017).

"Distraction": Another term which was related to mind-wandering was distraction, and one of the aims of focused attention meditation is to "disengage from distractors" (Simon et al., 2017) or to "keep the practitioner's attention away from distractors, such as par- 
ticular bodily sensations, feelings, and thoughts, which evoke mind-wandering" (Fujino et al., 2018).

"Rumination": Meditators were trained to avoid distractions in the sphere of rumination, a concept that seldom was explained. When rumination was explained, it was related to something "negative" e.g., "recurrent or repetitive negative thoughts" (Hernandez et al., 2018). Another example is: "Meditation also instructs people to maintain their attention on present experiences, which prevents them from engaging in recursive, ruminating processing of negative stimuli" (Shao et al., 2016).

\section{Attitudes}

Meditation training was not only about cultivating attention, awareness, and other wholesome qualities and avoiding unwholesome qualities such as mind-wandering. Meditation training also involved what some authors called specific attitudes to be maintained during meditation.

"Non-judgmental": In many studies, a non-judgmental attitude seemed to be the very definition of mindfulness meditation. "MBSR program is hypothesized to work by cultivating a particular non-judgmental attitude termed mindfulness" (Sevinc et al., 2018). "Mindfulness is defined as paying attention to the present moment without judgment" (Scheibner et al., 2017).

"Non-reactive": In some studies, a non-reactive attitude was encouraged. For example, the open monitoring meditation was described to "involve dispassionate observation or nonreactive monitoring of changing breath, thoughts, feelings, or bodily sensations" (Mahone et al., 2018). Fujino et al. (2018) linked nonjudgmental and non-reactive attitudes to the aim of "awareness of the present moment" in their description of meditation: “. .. meditators keep a non-reactive and non-judgmental awareness of anything that occurs in their experience of the present moment. While maintaining this awareness, the contents of experience such as bodily sensations, feelings, and thoughts are not distractors but simply contents for observation. However, if meditators react to or judge contents of their experience, as people tend to do automatically and habitually, they become distractors from awareness of the present moment" (Fujino et al., 2018).

"Receptive": A receptive attitude was often encouraged; for example, Berchovic-Ohana et al. (2016) described that one aim of mindfulness meditation is to cultivate "a receptive attitude towards all arising experiences".

"Detached": The final aim of meditation was in one study expressed as: "... the detached observation of bodily sensations, emotions and thoughts which is assumed to interrupt automatic responding and to increase behavioural flexibility" (Tomasino \& Fabbro, 2016). In another study, "detachment from autobiographical memory" was assumed to "play an important role in non-judgmental and non-reactive attitude" during open monitoring meditation (Fujino et al., 2018). The concept of detachment was further elaborated by Shao et al. (2016): "Theoretically, meditation emphasizes non-judgmental, open observations of thoughts, feelings, and stimuli from a non-self-referential perspective, allowing for the development of more self-detached, experiential and objective analysis of sensory events rather than focusing on the subjective affective values".

\section{Central Themes: Discussions}

The findings are related to networks and brain regions describing the cognitive, affective, and somatic domains of brain function. A fourth domain related to the self was also identified (Fig. 2). Note that in some contexts, all functions of the brain, such as emotion, self-referential processing, and interoception, are related to the cognitive domain. However, here, we limit the cognitive domain to functions such as thinking, attention, and executive functions.

\section{Cognitive Domain}

The cognitive quality that was most discussed in relation to meditation is attention, which was presented in a multitude of variants, e.g., attention (or attentional) readiness, (re)orienting, allocation, adjustment, regulation, maintenance, and switch or shift, as well as selective and sustained attention.

Another frequent cognitive quality was "control," for example executive, cognitive, attention, and inhibitory control as well as "controlled retrieval processes" (Engen et al., 2018), "conscious control of mental content" (Mahone et al., 2018), and "goal-directed, sustained control of behavior" (Taren et al., 2017). Taren et al. (2017) further discussed their results in term of cognitive control: "Consistent with our hypotheses, these findings broadly suggest that brief mindfulness training increases functional connectivity between a hub in the executive control network ... and dorsal and ventral corticolimbic circuits involved in cognitive control".

In the included articles, attention and control often were mentioned in tandem: "These results are consistent with our prediction that ... mindfulness exercises attention and awareness mechanisms, as well as inhibitory control, and task-related efficiency" (Tomasino \& Fabbro, 2016). "This seems to describe the role of these areas in the maintenance of the state of mental silence which requires fine-regulation 
Fig. 2 Domains of brain function. Schematic overview of the four different domains of brain function that were identified in the discussions of the included articles

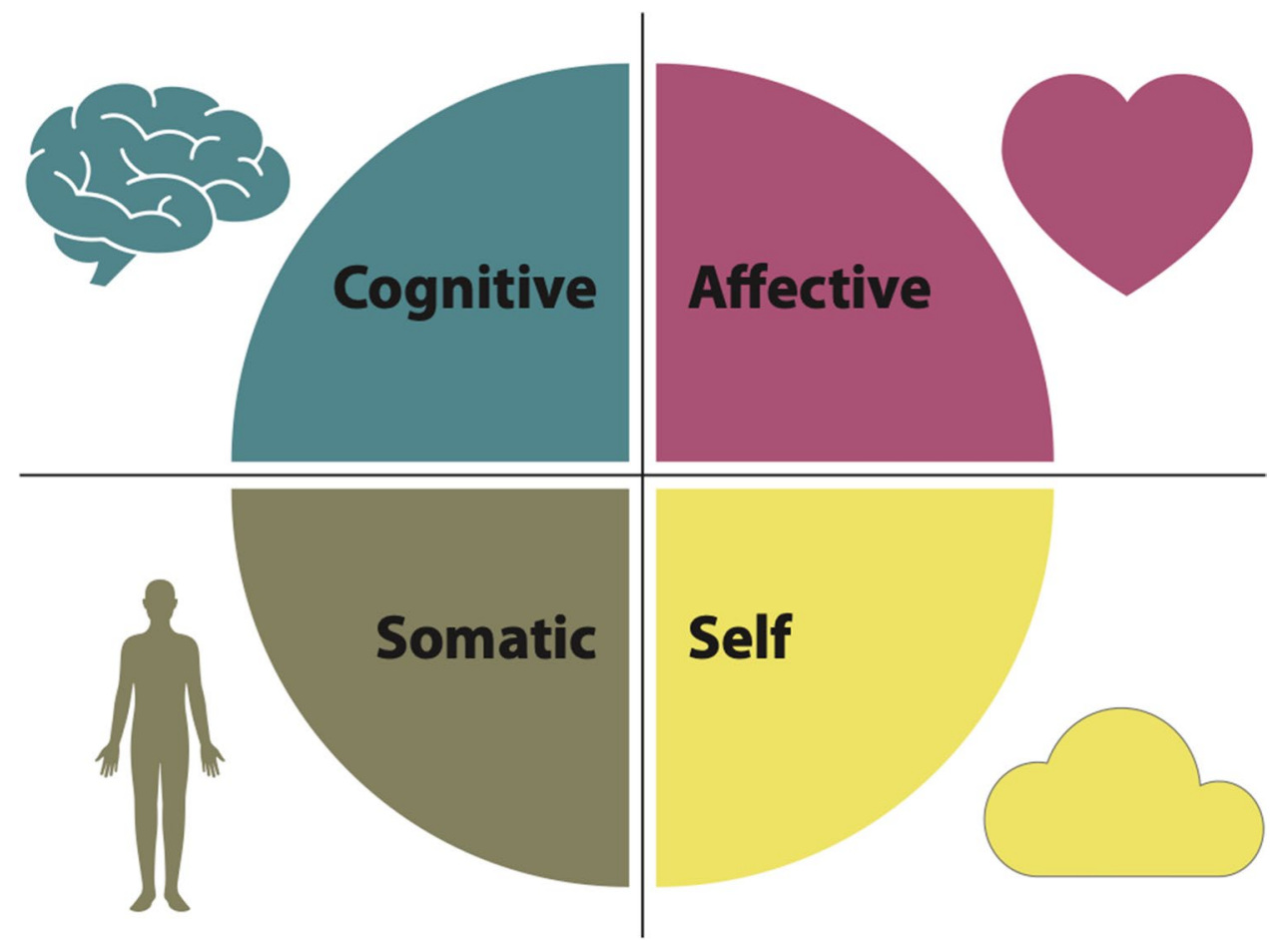

of emotion and top-down control of attention" (Hernandez et al., 2018).

\section{Affective Domain}

Many studies related meditation outcomes to regulation and control of affect, emotion, or mood, for example in terms of: "... cognitive control of emotion through strategies such as reappraisal and suppression" (Sevinc et al., 2018) or: "We speculate that mindfulness meditation training coupled the brain's default mode network with regulatory areas of prefrontal cortex ..., which facilitated more effective emotion regulation and stress resilience" (Creswell et al., 2016).

Some authors discussed their findings in terms of emotional and mental states, such as "attending to one's own emotions and mental states" (Tomasino \& Fabbro, 2016) or the "generation of positive emotional states" that were discussed in terms of brain function: "... our data could suggest that ventrolateral prefrontal and ventral anterior insular regions cooperate in the volitional generation of affective states ..." (Engen et al., 2018).

\section{Somatic Domain}

The discussed somatic domains of meditation practice included responses to external sensory stimuli but most frequently to interoception. The authors discussed their findings in terms of body sensations, sensory, body, or corporal awareness, and also "somatosensory attention"
(Lutz et al., 2016) and "sensory integration" (Tang et al., 2017), or further elaborated: “... the insular cortex likely represents the contents of the present-focused awareness, being associated with feedback regarding the interoceptive physiologic, exteroceptive somatic condition of the body and overall corporeal awareness" (Tomasino \& Fabbro, 2016).

\section{Self}

A major trend in the discussion of fMRI results from meditation studies was the relation to the self, using terminology such as self-referential or self-related or self-awareness. The discussion of the self is further elaborated as "process-oriented focus on the self during meditation" (Creswell et al., 2016), "reduction of self-related processing" (BerkovichOhana et al., 2016; Engen et al., 2018), or “down-regulation of cognitive self-referential ... regions ... during mindful self-awareness" (Lutz et al., 2016). Lutz et al. (2016) also pointed out the "distinction between mindful self-awareness and cognitive self-reference." Findings in certain brain regions were often guiding the interpretation in terms of the self: "Thus, the increased positive connectivity from the pons to the posterior cingulate cortex/precuneus following meditation training may indicate an enhanced self-referential affective regulatory system, possibly following a shift from a narrative, self-evaluative approach to a non-judgmental, self-aware approach" (Shao et al., 2016). 


\section{Common Features: Processes and Interpretations}

Most studies (15 of 21) described brain function in relation to meditation in terms of "processes." Table 2 lists all functions that were discussed in terms of processes in the cognitive, affective, somatic, and the self domains, for example "attention processes" and "self-related processes".

The discussions of fMRI results from these studies on meditation practice generally followed the conventional approach for fMRI research in general. Activation or functional connectivity was observed in a certain region or network, thereby the authors allocated functions to these brain structures based on previous task-based literature. Here, for example, the anterior cingulate/medial prefrontal cortices were attributed to top-down attention and emotional regulation or control: "The rostral anterior cingulate cortex/medial prefrontal cortex activation in meditators has been attributed to top-down attention regulation processes needed to focus attention on the meditative process and to the need to inhibit distracting factors from the mind and the environment as well as to a strengthening of top-down emotion control" (Hernandez et al., 2018).

Other authors discussed their findings in less detail: "We found significantly increased functional connectivity between occipital, temporal and frontal regions, which may suggest that meditation training mainly improves attention, emotional, cognitive and reward processing" (Tang et al., 2017).

\section{Discussion}

Davidson and Kaszniak (2015) raised several methodological issues in the study of mediation. Although this research field has moved forward with respect to descriptive clarity and methodology, we found several issues to advance.

\section{Provide Clear and Unambiguous Definitions of Constructs and Practices}

Meditation is not one single entity. It is multifaceted, stemming from many different traditions such as Hinduism, Buddhism, Taoism, Christianity, Judaism, and Sufism. These traditions, despite their similarities, differ in their world view and intention, and several methods for meditative absorption and contemplation can be applied in each tradition. In this review, we observed that meditation, as the general target for the field of research, was based on various contemplative

Table 2 Processes in the cognitive, affective, somatic, and the self domains

\begin{tabular}{|c|c|c|}
\hline Domain & Processes & Reference \\
\hline \multirow[t]{10}{*}{ Cognitive } & Cognitive & Dodich et al. (2019), Sevinc et al. (2018), Simon et al. (2017), Tang et al. (2017), Xiao et al. (2019) \\
\hline & Metacognitive & Ellamil et al. (2016) \\
\hline & Executive & Mahone et al. (2018) \\
\hline & Information & Dodich et al. (2019), Mahone et al. (2018), Tang et al. (2017), Xiao et al. (2019) \\
\hline & Regulatory & Shao et al. (2016) \\
\hline & Attention & $\begin{array}{l}\text { Dodich et al. (2019), Engen et al. (2018), Hernandez et al. (2018), Jang et al. (2018), Scheibner et al. (2017), } \\
\text { Tang et al. (2017) Taren et al. (2017) }\end{array}$ \\
\hline & Spontaneous thought & Ellamil et al. (2016) \\
\hline & Retrieval & Engen et al. (2018) \\
\hline & Linguistic & Engen et al. (2018), Liou et al. (2016) \\
\hline & Learning & Bauer et al. (2019) \\
\hline \multirow[t]{4}{*}{ Affective } & Affective & Shao et al. (2016), Tang et al. (2017) \\
\hline & Socio-affective & Engen et al. (2018) \\
\hline & Emotion & Bauer et al. (2019), Tang et al. (2017), Taren et al. (2017), Xiao et al. (2019) \\
\hline & Reward & Hernandez et al. (2018), Tang et al. (2017) \\
\hline \multirow[t]{4}{*}{ Somatic } & Sensory & Hernandez et al. (2018), Tang et al. (2017), Xiao et al. (2019) \\
\hline & Visual & Berkovich-Ohana et al. (2016), Tang et al. (2017), Xiao et al. (2019) \\
\hline & Interoceptive & Jang et al. (2018), Xiao et al. (2019) \\
\hline & Salience & Taren et al. (2017) \\
\hline \multirow[t]{4}{*}{ Self } & Self-related & $\begin{array}{l}\text { Berkovich-Ohana et al. (2016), Engen et al. (2018), Scheibner et al. (2017), Simon et al. (2017), Xiao et al. } \\
\text { (2019) }\end{array}$ \\
\hline & Self-reflective & Lutz et al. (2016) \\
\hline & Self-referential & Kim et al. (2019), Scheibner et al. (2017), Shao et al. (2016), Simon et al. (2017), Xiao et al. (2019) \\
\hline & Self-focused & Shao et al. (2016) \\
\hline
\end{tabular}


traditions where meditation was taught and practiced differently. With few exceptions, the applied traditions were not clearly described, neither concerning philosophical aspects, in terms of the different world views, nor with a common scientific framework for descriptions of the meditation practices. The need for clear definitions of relevant concepts and clarification of ambiguous terms and constructs such as meditation and mindfulness along with the concomitant mental states has been addressed previously (Awasthi, 2013; Cardoso et al., 2004). Awasthi (2013) argued that ignoring the "underlying philosophical aspects of meditation" has consequences for the design and results, and they suggested that "incorporating the ontological definition of meditation will provide a much-needed context and framework for the interventions borrowed from or based on meditation". We argue that our present study provides further support for this notion.

In a first attempt to construct a general taxonomy of meditation practices from different traditions, two common meditation practices were characterized: focused attention (FA) meditation involving attention to a specific object, for example the breath, and open monitoring $(\mathrm{OM})$ meditation, involving awareness of anything that comes into experience (Lutz et al., 2008). To further generalize the taxonomy, three different families of meditation practices were defined: (1) the attentional family including FA and OM, (2) the constructive family including for example loving kindness and compassion meditations, and (3) the deconstructive family including different sorts of insight meditations (Dahl et al., 2015). Other theoretical models for meditation research have also been proposed (Nash \& Newberg, 2013).

In the present review, which was based on how meditation was described in current fMRI research, we identified four different intention-based dimensions for meditation practice: (1) The present moment, (2) Wholesome qualities to cultivate, (3) Unwholesome qualities to avoid, and (4) Attitudes. We labelled certain qualities as wholesome because they were described by the authors either as conducive for meditation practice and/or health-promoting. These dimensions referred both to experiences during meditation (state) and outcomes of meditation practice (trait) depending on the objective of the respective study.

The concept of the present moment was not always defined in the reviewed articles. If defined, the present moment was related to sensory experiences of body and mind. These authors defined the present moment in terms of its content, for example sensory experiences in different body areas, and not in terms of its duration. Studies of the duration of the present moment would be a research topic of its own since people that meditate have reported an altered perception of time (Kramer et al., 2013; Wittmann et al., 2014).
The wholesome qualities of attention and awareness were often described as antidotes to the unwholesome qualities of mind-wandering, distraction, and rumination. Note that, if rumination was explained, it was related to something with negative attributes. The word negative in this context is ambiguous since it could relate both to something unwholesome and something unpleasant. However according to this definition, repetitive thoughts that are perceived as pleasant could also be categorized as rumination and thus considered unwholesome.

The quality of wholesome emotion was most commonly associated with health-promoting effects and pleasant mental states, i.e., positive affect. However, one study in the present review investigated meditation with the explicit intention to develop the wholesome qualities of loving kindness (mettā) and compassion (Engen et al., 2018). Furthermore, some studies described energy as a wholesome quality. Here energy seemed to relate to what is sometimes called rapture (prīti), one of the factors for meditative absorption (dhyāna), not to be mixed up with "energy in pursuit of the good" (vīrya), also translated as ardour. In other studies, mental silence was described as an objective of meditation. The degree of mental silence ranged from quieting "the thinking mind" (Jang et al., 2018) to "thoughtless awareness" (Hernandez et al., 2018). It is a common misunderstanding by novices that meditation in general is centered around the attainment of mental silence, to be without thoughts, a mental state that is sometimes related to meditative absorption (dhyāna). On the contrary, in many traditions, meditation is about turning towards direct experience in whatever form it takes, and reflective thinking is an integral part in insight (vipassanā) meditation (Kamalashila, 2012), described as the deconstructive family by Dahl et al. (2015).

Some specific qualities were described as attitudes by the authors in the present review. According to the general definition, attitude can refer both to physical posture and mental approach. In our review, the following mental approaches were mentioned: non-judgemental, non-reactive, receptive, and detached. Here, non-judgemental could relate to an attitude of turning towards whatever is occurring in experience without judging it as good or bad. Non-reactive could be an attitude of seeing things as they are without reacting with proliferating thoughts, and receptive could relate to an open and susceptible attitude, especially towards the wholesome effects of meditation. The term detached is, however, problematic since it could be associated with being indifferent or even alienated. The term might have been confused with the term "non-attachment" (alobha), which literally means non-craving, which is a term that is related to contentment rather than indifference (Subhuti, 2015). Note that the terms, here denoted as attitudes, were frequently listed but seldom explained and defined in the reviewed studies. 
What we identified as intention-based dimensions have a striking resemblance to ancient Buddhist psychology according to the Abhidharma traditions that described the human mind by means of mental factors or events (Jacobs, 2017; Sangharakshita, 2012). Although different schools proposed different lists of mental events, the lists are similar and to a large extent overlapping. The present moment, according to the Yogacara school, adhere to the five Universal mental events (sarvatraga caitta dharma) that are present in every moment, i.e., contact (sparśa), feeling tone (vedanā), perception (samjū̃ā), volition (cetanā), and attention (manaskāra), where the last item represents the present mind moment as a whole (Subhuti, 2015). Focusing on present moment sensations can help the meditator to practice attention and awareness, but also to observe the perpetual flow of ever-changing sense experiences and mental events, the so-called "direct experience of reality". Therefore, depending on the meditator's intention, meditation on the present moment, or the five Universal mental events, can be classified into either the Attentional family or the Deconstructive family described by Dahl et al. (2015). However, in this review, most studies investigated the attentional aspects of the present moment.

Wholesome qualities to cultivate, unwholesome qualities to avoid, and attitudes resemble the ethical dimension of Buddhist psychology that describes skilful, or wholesome, mental events or states (kuśala caitta dharma), and afflictions (kleśa). Note that Buddhist ethics encompasses actions of body, speech, and mind, and in this context (fMRI studies on meditation), it is the mind which is the focus of investigation while actions or outcomes of body and speech are not considered. Meditation practices that aim to develop and maintain wholesome mental states relate to the Constructive family (Dahl et al., 2015). By similar comparison, meditation practices that aim to eradicate unwholesome mental states and prevent them from coming back relate to the Deconstructive family. Future studies investigating a specific practice would benefit from reflecting on the original intention behind each practice and clearly defining the intention in terms of outcome measures. In addition, we suggest welldefined aims in terms of the cultivation or eradication of any qualities, mental states, attitudes, or somatic elements of practice. Finally, it would be helpful to define any ethical aims or outcomes associated with, or intended in, the implementation of the chosen practice in body, speech, and mind and to use those to inform the choice of outcome measures used in the study.

\section{Measures of Subjective Experience}

In the present analysis, we found that meditation was strikingly often described as an "experience". Experience was mostly related to the present moment, as in "the present moment experience". However, very few authors evaluated subjective experience and if they did, the assessments were simply confirmatory in nature; for example, the participants were asked to confirm if desired meditative states were achieved during fMRI or not. The experiential assessments conducted in the studies included in this review ranged from numerical (ratings) to qualitative (interviews). However, half of the studies made no form of assessment of subjective experience.

According to Davidson and Kaszniak (2015), it is important not to rely entirely on third-person assessments, but to also assess experience by means of first-person reporting, as it has been shown to be useful for the detection and interpretation of neural processes (Lutz et al., 2002). Nash and Newberg (2013), however, favored the use of well-established and commonly accepted third-person methods to first-person reports.

When studying the neural basis of behavior, including mental experiences, we agree that it is critical to include relevant (psychological) assessments of the behavior or experience itself such as ratings of individuals' experiences on one or several dimensions. Many of the commonly used questionnaires have been shown to be of poor quality or lacking in validity (Park et al., 2013). However, new methods to increase the precision of these instruments using Rasch analysis have been suggested (Medvedev et al., 2016, 2017). Further development and validation of new instruments designed to assess first-person experience are much needed in this field. In addition, thorough consideration should be given not only to first-person reports on the dimensions of mindfulness but also to the instructions given to participants during the period of data collection. Are the experimental instructions eliciting a short-term state of mindful awareness, also called a deliberate or intentional state of mindfulness? Are they designed to evaluate the individual's overall disposition as a result of mindfulness practice, also called trait mindfulness? Some methods for distinguishing between state and trait have been suggested using generalizability theory as well as through refining experimental design (Duan \& Li, 2016; Truong et al., 2020). This is of particular relevance to neuroimaging research on meditation since the technique of meditation and the long-term dispositional traits sometimes seem to be confused with the state of meditation (Awasthi, 2013). Thus, not separating meditation techniques or traits from meditative states when studying the neural correlates of meditation may lead to erroneous conclusions.

In our view, the inclusion of psychological assessments as a manipulation check comes with some methodological considerations. For example, when including behavioral assessments (e.g., ratings of experiences), these should be carried out at least pre- and post-scanning. Furthermore, we suggest that assessments during scanning provide important information and should also be included if possible. In 
the case that an undisturbed resting-state scan is chosen to allow for deeper states of absorption, we recommend a firstperson post-scan assessment of the quality and depth of the meditation in stages (e.g., after the "ringing of bells one, two, or three in the scanner"), which may at least provide more nuanced and granular information by which to assess the experience. In a similar way, consideration should be given for the inclusion of individual journals or dairies kept over the duration the study which may hold the potential for encoding into useful variables assessing experience. These continuous measurements of experience during scanning can be used as time-series data when analyzing processes. Thus, we recommend that relevant continuous assessments of experience pre-, during, and post-scanning should be given special consideration when designing a study protocol. This said, even if it has been shown that third-person measurements of EEG synchrony patterns were associated with firstperson reported degrees of preparation and immediateness of perception (Lutz et al., 2002), potential lack of credibility in first-person reports must be acknowledged. Especially, in meditation research, there is a risk of the participants wanting to perform well. Another risk is they respond from a position of knowing the answer from, e.g., reading popular literature on meditation or from long-term experience in meditation training. In novices, there is a risk of not being able to fully describe their own mental states and sensory experiences.

Regarding assessment of subjective experience, three conclusions can be drawn from the current fMRI research of meditation: (a) assessment of the subjective experience was often lacking, (b) assessment of subjective experience was inconsistent across studies, and (c) study designs displayed large heterogeneity across studies. Consequently, it is challenging to perform comparisons between studies (e.g., for meta-analytic purposes).

\section{Correct Assessment of Processes: State vs. Process}

It was common for authors to describe brain function in relation to meditation as different kinds of processes. According to Oxford dictionary of psychology, a process is defined as "a sequence of events leading to some change or alteration in the state of a dynamic system". In this context, it is relevant to distinguish between process in which something is processed, and state in which a condition is maintained for a period. In psychology and neuroscience, processes are often shorter in duration (i.e., seconds, minutes, or fractions thereof, although processes can also span years by definition) compared to states, which are typically minutes up to years (Thornton et al., 2019). A state, "an attribute of a person-in-a-situation", can be viewed as a temporary condition of shorter duration than a trait (Steyer et al., 2015). In contrast, traits are characteristics that are more stable over long stretches of time (i.e., years up to lifespan). It should be stressed that the differentiation between these concepts is not merely a matter of time scale. To avoid the confusion concerning process, state, or trait, we suggest specifying a priori how the design, data, and conclusions relate to these concepts.

In the context of meditation, the study of a process should invariably include an element of time, whereas the in study of states or traits the time dimension may reach outside the window of the experiments which, if longitudinal, are typically no longer than 8 weeks. Thus, when studying a process, the temporal component should be considered and modeled. Although, fMRI data is inherently time dependent in the form of blood oxygen leveldependent (BOLD) responses to neural activity, the data are usually concatenated over the time of scanning during analysis. In addition, to improve the quality and depth of the absorptive state, many study protocols have intentionally avoided event-based design, thus eliminating the temporal tracking of the very sequence of events which allow for the critical evaluation of a process. This means that the dimension of time is not fully considered in many fMRI studies, yet researchers continue to interpret and draw conclusions about processes.

To make a proper interpretation of brain function in terms of processes, the results must include the component time either in a regional dynamic model or models reflecting interactions between several brain regions or within wholebrain networks. There are several methods to approach this aim. One approach is to investigate regional BOLD time courses whose dynamics can be explained by biomechanistical models (Havlicek et al., 2017; Lundengård et al., 2016). Other approaches are based on time-varying functional connectivity (TVFC) or dynamic connectivity (Calhoun et al., 2014; Deco et al., 2011). In this review, some studies had a dynamic perspective in their regional or whole-brain analyses. Ellamil et al. (2016) investigated regional dynamic properties of the BOLD time series by investigations of the time-to-peak in response to spontaneous thought. Shao et al. (2016) used dynamic causal modeling to determine the directionality of the functional connectivity between several brain regions, and Escrichs et al. (2019) estimated whole-brain network stability and dynamic complexity based on the intrinsic ignition framework (Deco \& Kringelbach, 2017; Deco et al., 2017). Combinations of detailed mechanistic and large-scale dynamic approaches may add an additional facet to the investigation of mental processes related to meditation, for example brain metastability during meditation (Cavanna et al., 2018). However, they should be used with a clear predefined intention as these methods are themselves riddled with technical challenges and limits as to their interpretation in this context in particular (GonzalezCastillo \& Bandettini, 2018; Lurie et al., 2020). 
Another critical issue that arises is that of how processes are detected in neuroimaging. Given that the strong suit of fMRI is spatial localization in comparison to its poor temporal resolution, and vice versa for EEG, simultaneous acquisition of fMRI and EEG data represents another interesting option when studying processes. By combining fMRI and EEG (simultaneous recordings), both the localization (fMRI) and dynamics (EEG) of a process can be captured. Simultaneous fMRI-EEG has previously been applied to the study of meditation (Panda et al., 2016; Winter et al., 2019).

Other methodological options that could be of interest when studying meditation are transcranial magnetic stimulation (TMS) in combination with fMRI/EEG. Activating or deactivating brain regions by means of TMS followed by fMRI/EEG recordings may further the knowledge concerning the neural underpinnings of meditation both in terms of transient states and processes.

\section{Avoid the Risk of Overinterpretation}

We found that discussions in the reviewed articles gravitated around networks and brain regions that described cognitive, affective, and somatic domains of brain function. A fourth domain related to the self was also identified, however often undefined. From our analyses, it can be concluded that meditation is discussed from several perspectives in the recent literature on fMRI and meditation. Typically, brain activation or functional connectivity in certain regions or networks was assigned to certain cognitive, affective, somatic, or self-related functions that previous studies have linked to these regions or networks. Interpretations and conclusions were based on previous research mainly applying cognitive paradigms or meditation research that in turn cites previous cognitive research. There is evidence of a correspondence between networks that are connected during rest and networks that are activated during cognitive tasks, such as working memory and attention (Smith et al., 2009). It has also been shown that resting-state functional connectivity can predict task-based activity (Mennes et al., 2010). However, other work indicates that resting-state and task-based networks for certain functions are spatially overlapping but relate to different neurophysiological processes (Parker \& Razlighi, 2019) and that resting-state connectivity does not determine cognitive performance (Davis et al., 2017). The discussion on the relationship between resting-state and taskbased networks is important in the present context because what the mind is doing during meditation is to a large extent unknown. To avoid confusion over experiment design and limits on the interpretation of results, we recommend the complementary use of both resting-state and task-based design in logical conjunction to allow for translation and association with earlier cognitive task-based designs in the literature, as for example was done by Berkovich-Ohana et al. (2016) in the current review.

Davidson and Kaszniak (2015) also pointed out the need for explicit descriptions of what practices and mental states are investigated and cautiousness in interpreting neuroimaging of those mental states. As stated above, we noticed a lack of clarity in definitions of constructs and practices, which perpetuated in the interpretation of the results. For example, many authors described meditation in terms of the present moment. However, with few exceptions (e.g., Lutz et al., 2016; Scheibner et al., 2017), the authors did not relate the present moment to certain mental states that could be investigated by fMRI. There was also generally a lack of assessment of subjective experience and behavioral outcomes hypothetically related to meditation, such as attention, awareness, stress resilience, and executive control, which could have been associated with the measured brain function. We agree with Van Dam and co-authors (2018) who urged meditation researchers to mind the hype and warned against overly simplistic interpretations of complex neural processes involved in different meditation practices.

In addition to the experimental paradigm, other factors that may increase the risk of overinterpretation concern the participants. Two factors should be highlighted: the lack of statistical power and small sample sizes and individual variability regarding knowledge and skill in meditation. Lack of statistical power and small sample sizes has been pointed out as a limitation of many fMRI studies (e.g., Bossier et al., 2020; Turner et al., 2018). Small sample sizes may lead to difficulties in replication and an inability to generalize the results. Given that relatively small samples are common in fMRI studies, the individual variability in experience, skill, or knowledge may lead to errors and overinterpretations of the results. According to the law of large numbers, studies of small sample sizes show higher variance. Therefore, the participant groups should be as homogeneous as possible (if not, then individual variation should be studied) regarding experience, knowledge, and skill regarding the form of meditation studied. Error and heterogeneity, that are not planned for or considered in the analysis, may lead to overinterpretation or erroneous conclusions (Dennis et al., 2019; Xie, 2013).

\section{Limitations and Future Research}

The strength of this study was that it reported how fMRI research on meditation was described, performed, and discussed by the authors themselves. However, this study also had its limitations. The choice of search phrases might have caused inappropriate exclusions of studies applying, e.g., mindfulness, yoga, and prayer, which could have similarities with the included studies but didn't use meditation in their search fields. The lumping together of studies from diverse 
traditions might have caused bias either towards traditions represented by many studies, e.g., MBSR and developments thereof, or by singular studies, e.g., Tibetan Nyingma.

We are also aware that we did not cover all emergent aspects in this growing field of fMRI studies on meditation. In addition to the observations and suggestions for future research discussed above, we would like to echo some important suggestions made in previous criticisms and discussions on meditation and therapeutic interventions such as the necessary inclusion of waitlist or active control groups, careful curation of participant groups based on length, duration, and frequency of individual meditation practices.

Supplementary Information The online version contains supplementary material available at https://doi.org/10.1007/s12671-021-01782-7.

Author Contribution ME: designed and executed the study and wrote the first draft of the paper. JW: collaborated with the writing of the study and editing of the final manuscript. RS: collaborated with the writing of the study and editing of the final manuscript. All authors approved the final version of the manuscript for submission.

Funding Open access funding provided by Linköping University.

\section{Declarations}

Conflict of Interest The authors declare no competing interests.

Open Access This article is licensed under a Creative Commons Attribution 4.0 International License, which permits use, sharing, adaptation, distribution and reproduction in any medium or format, as long as you give appropriate credit to the original author(s) and the source, provide a link to the Creative Commons licence, and indicate if changes were made. The images or other third party material in this article are included in the article's Creative Commons licence, unless indicated otherwise in a credit line to the material. If material is not included in the article's Creative Commons licence and your intended use is not permitted by statutory regulation or exceeds the permitted use, you will need to obtain permission directly from the copyright holder. To view a copy of this licence, visit http://creativecommons.org/licenses/by/4.0/.

\section{References}

Awasthi, B. (2013). Issues and perspectives in meditation research: In search for a definition. Frontiers in Psychology, 3, 613. https://doi. org/10.3389/fpsyg.2012.00613

Bauer, C. C. C., Whitfield-Gabrieli, S., Díaz, J. L., Pasaye, E. H., \& Barrios, F. A. (2019). From state-to-trait meditation: Reconfiguration of central executive and default mode networks. eNeuro, 6 , 1-17. https://doi.org/10.1523/ENEURO.0335-18.2019

Berkovich-Ohana, A., Harel, M., Hahamy, A., Arieli, A., \& Malach, R. (2016). Alterations in task-induced activity and resting-state fluctuations in visual and DMN areas revealed in long-term meditators. NeuroImage, 135, 125-134. https://doi.org/10.1016/j.neuro image.2016.04.024

Bossier, H., Roels, S. P., Seurinck, R., Banaschewski, T., Barker, G. J., Bokde, A. L. W., Quinlan, E. B., Desrivieres, S., Flor, H., Grigis, A., Garavan, H., Gowland, P., Heinz, A., Ittermann, B., Martinot,
J. L., Artiges, E., Nees, F., Orfanos, D. P., Poustka, L., Frohner Dipl-Psych, J. H., Smolka, M. N., Walter, H., Whelan, R., Schumann, G., Moerkerke, B., \& Consortium, I. (2020). The empirical replicability of task-based fMRI as a function of sample size. Neuroimage, 212, 116601. https://doi.org/10.1016/j.neuroimage. 2020.116601

Calhoun, V. D., Miller, R., Pearlson, G., \& Adali, T. (2014). The chronnectome: Time-varying connectivity networks as the next frontier in fMRI data discovery. Neuron, 84(2), 262-274. https:// doi.org/10.1016/j.neuron.2014.10.015

Cardoso, R., de Souza, E., Camano, L., \& Leite, J. R. (2004). Meditation in health: An operational definition. Brain Research Protocols, 14(1), 58-60. https://doi.org/10.1016/j.brainresprot.2004. 09.002

Cavanna, F., Vilas, M. G., Palmucci, M., \& Tagliazucchi, E. (2018). Dynamic functional connectivity and brain metastability during altered states of consciousness. NeuroImage, 180(Pt B), 383-395. https://doi.org/10.1016/j.neuroimage.2017.09.065

Crescentini, C., Fabbro, F., \& Tomasino, B. (2017). Editorial special topic: Enhancing brain and cognition through meditation [editorial]. Journal of Cognitive Enhancement, 1, 81-83. https://doi.org/ 10.1007/s41465-017-0033-4

Creswell, J. D., Taren, A. A., Lindsay, E. K., Greco, C. M., Gianaros, P. J., Fairgrieve, A., Marsland, A. L., Brown, K. W., Way, B. M., Rosen, R. K., \& Ferris, J. L. (2016). Alterations in resting-state functional connectivity link mindfulness meditation with reduced interleukin-6: A randomized controlled trial. Biological Psychiatry, 80(1), 53-61. https://doi.org/10.1016/j.biopsych.2016.01.008

Dahl, C. J., Lutz, A., \& Davidson, R. J. (2015). Reconstructing and deconstructing the self: Cognitive mechanisms in meditation practice. Trends in Cognitive Sciences, 19(9), 515-523. https://doi.org/ 10.1016/j.tics.2015.07.001

Davidson, R. J., \& Kaszniak, A. W. (2015). Conceptual and methodological issues in research on mindfulness and meditation. American Psychologist, 70(7), 581-592. https://doi.org/10.1037/ a0039512

Davis, S. W., Stanley, M. L., Moscovitch, M., \& Cabeza, R. (2017). Resting-state networks do not determine cognitive function networks: A commentary on Campbell and Schacter (2016). Language, Cognition and Neuroscience, 32(6), 669-673. https://doi. org/10.1080/23273798.2016.1252847

Deco, G., Jirsa, V. K., \& McIntosh, A. R. (2011). Emerging concepts for the dynamical organization of resting-state activity in the brain. Nature Reviews Neuroscience, 12(1), 43-56. https://doi. org/10.1038/nrn2961

Deco, G., \& Kringelbach, M. L. (2017). Hierarchy of information processing in the brain: A novel 'intrinsic ignition' framework. Neuron, 94(5), 961-968. https://doi.org/10.1016/j.neuron.2017.03.028

Deco, G., Tagliazucchi, E., Laufs, H., Sanjuan, A., \& Kringelbach, M. L. (2017). Novel intrinsic ignition method measuring local-global integration characterizes wakefulness and deep sleep. eNeuro, 4(5). https://doi.org/10.1523/ENEURO.0106-17.2017

Dennis, B., Ponciano, J. M., Taper, M. L., \& Lele, S. R. (2019). Errors in statistical inference under model misspecification: Evidence, hypothesis testing, and AIC. Frontiers in Ecology and Evolution, 7, 372. https://doi.org/10.3389/fevo.2019.00372

Dodich, A., Zollo, M., Crespi, C., Cappa, S. F., Martinez, D. L., Falini, A., \& Canessa, N. (2019). Short-term Sahaja Yoga meditation training modulates brain structure and spontaneous activity in the executive control network. Brain and Behavior, 9(1). https://doi. org/10.1002/brb3.1159

Dorjee, D. (2016). Defining contemplative science: The metacognitive self-regulatory capacity of the mind, context of meditation practice and modes of existential awareness. Frontiers in Psychology, 7, 1788. https://doi.org/10.3389/fpsyg.2016.01788 
Duan, W., \& Li, J. (2016). Distinguishing dispositional and cultivated forms of mindfulness: Item-level factor analysis of five-facet mindfulness questionnaire and construction of short inventory of mindfulness capability. Frontiers in Psychology, 7, 1348. https:// doi.org/10.3389/fpsyg.2016.01348

Ellamil, M., Fox, K. C., Dixon, M. L., Pritchard, S., Todd, R. M., Thompson, E., \& Christoff, K. (2016). Dynamics of neural recruitment surrounding the spontaneous arising of thoughts in experienced mindfulness practitioners. NeuroImage, 136, 186-196. https://doi.org/10.1016/j.neuroimage.2016.04.034

Engen, H. G., Bernhardt, B. C., Skottnik, L., Ricard, M., \& Singer, T. (2018). Structural changes in socio-affective networks: Multimodal MRI findings in long-term meditation practitioners. Neuropsychologia, 116(Pt A), 26-33. https://doi.org/10.1016/j.neuro psychologia.2017.08.024

Escrichs, A., Sanjuan, A., Atasoy, S., Lopez-Gonzalez, A., Garrido, C., Camara, E., \& Deco, G. (2019). Characterizing the dynamical complexity underlying meditation. Frontiers in Systems Neuroscience, 13. https://doi.org/10.3389/fnsys.2019.00027

Evans, S., Wyka, K., Thorpe Blaha, K., \& Allen, E. S. (2018). Selfcompassion mediates improvement in well-being in a mindfulness-based stress reduction program in a community-based sample. Mindfulness, 9, 1280-1287. https://doi.org/10.1007/ s12671-017-0872-1

Fox, K. C. R., \& Cahn, B. R. (2018). Meditation and the brain in health and disease. MindRxiv. https://doi.org/10.31231/osf.io/m2sez

Fox, K. C. R., Dixon, M. L., Nijeboer, S., Girn, M., Floman, J. L., Lifshitz, M., Ellamil, M., Sedlmeier, P., \& Christoff, K. (2016). Functional neuroanatomy of meditation: A review and meta-analysis of 78 functional neuroimaging investigations. Neuroscience \& Biobehavioral Reviews, 65, 208-228. https://doi.org/10.1016/j. neubiorev.2016.03.021

Fujino, M., Ueda, Y., Mizuhara, H., Saiki, J., \& Nomura, M. (2018). Open monitoring meditation reduces the involvement of brain regions related to memory function. Scientific Reports, 8(1), 9968. https://doi.org/10.1038/s41598-018-28274-4

Gonzalez-Castillo, J., \& Bandettini, P. A. (2018). Task-based dynamic functional connectivity: Recent findings and open questions. NeuroImage, 180(Pt B), 526-533. https://doi.org/10.1016/j.neuro image.2017.08.006

Havlicek, M., Ivanov, D., Roebroeck, A., \& Uludag, K. (2017). Determining excitatory and inhibitory neuronal activity from multimodal fMRI data using a generative hemodynamic model. Frontiers in Neuroscience, 11, 616. https://doi.org/10.3389/fnins.2017. 00616

Hernandez, S. E., Barros-Loscertales, A., Xiao, Y., Gonzalez-Mora, J. L., \& Rubia, K. (2018). Gray matter and functional connectivity in anterior cingulate cortex are associated with the state of mental silence during Sahaja Yoga meditation. Neuroscience, 371, 395-406. https://doi.org/10.1016/j.neuroscience.2017.12.017

Jacobs, B. (2017). The original buddhist psychology. North Atlantic Books.

Jang, J. H., Kim, J. H., Yun, J. Y., Choi, S. H., An, S. C., \& Kang, D. H. (2018). Differences in functional connectivity of the insula between brain wave vibration in meditators and non-meditators. Mindfulness ( $n$ y), 9(6), 1857-1866. https://doi.org/10.1007/ s12671-018-0928-x

Jao, T., Li, C. W., Vertes, P. E., Wu, C. W., Achard, S., Hsieh, C. H., Liou, C. H., Chen, J. H., \& Bullmore, E. T. (2016). Large-scale functional brain network reorganization during Taoist meditation. Brain Connectivity, 6(1), 9-24. https://doi.org/10.1089/brain. 2014.0318

Kamalashila. (2012). Buddhist meditation; Tranquility, imagination and insight (3rd ed.). Windhorse Publications.

Kim, H. C., Tegethoff, M., Meinlschmidt, G., Stalujanis, E., Belardi, A., Jo, S., Lee, J., Kim, D. Y., Yoo, S. S., \& Lee, J. H. (2019).
Mediation analysis of triple networks revealed functional feature of mindfulness from real-time fMRI neurofeedback. NeuroImage, 195, 409-432. https://doi.org/10.1016/j.neuroimage.2019.03.066

Kramer, R. S., Weger, U. W., \& Sharma, D. (2013). The effect of mindfulness meditation on time perception. Consciousness and Cognition, 22(3), 846-852. https://doi.org/10.1016/j.concog.2013. 05.008

Leyland, A., Rowse, G., \& Emerson, L. M. (2019). Experimental effects of mindfulness inductions on self-regulation: Systematic review and meta-analysis. Emotion, 19(1), 108-122. https://doi. org/10.1037/emo0000425

Liou, C.-H., Hsieh, C.-H., Hsieh, C.-W., Wang, C.-H., Chen, J.-H., \& Lee, S.-C. (2016). A multidimensional quantum model of brain activity: The exploration of increased neural energy states in Daoist meditation NeuroQuantology 14(3), 524-534 https://doi.org/ 10.14704/nq.2016.14.3.930

Lundengård, K., Cedersund, G., Sten, S., Leong, F., Smedberg, A., Elinder, F., \& Engström, M. (2016). Mechanistic mathematical modeling tests hypotheses of the neurovascular coupling in fMRI. PLoS Computational Biology, 12(6), e1004971. https://doi.org/10. 1371/journal.pcbi.1004971

Lurie, D. J., Kessler, D., Bassett, D. S., Betzel, R. F., Breakspear, M., Kheilholz, S., Kucyi, A., Liegeois, R., Lindquist, M. A., McIntosh, A. R., Poldrack, R. A., Shine, J. M., Thompson, W. H., Bielczyk, N. Z., Douw, L., Kraft, D., Miller, R. L., Muthuraman, M., Pasquini, L., ... Calhoun, V. D. (2020). Questions and controversies in the study of time-varying functional connectivity in resting fMRI. Network Neuroscience, 4(1), 30-69. https://doi.org/ 10.1162/netn_a_00116

Lutz, A., Lachaux, J. P., Martinerie, J., \& Varela, F. J. (2002). Guiding the study of brain dynamics by using first-person data: Synchrony patterns correlate with ongoing conscious states during a simple visual task. Proceedings of the National Academy of Sciences of the United States of America, 99(3), 1586-1591. https://doi.org/ 10.1073/pnas.032658199

Lutz, A., Slagter, H. A., Dunne, J. D., \& Davidson, R. J. (2008). Attention regulation and monitoring in meditation. Trends in Cognitive Sciences, 12(4), 163-169. https://doi.org/10.1016/j.tics.2008.01. 005

Lutz, J., Bruhl, A. B., Scheerer, H., Jancke, L., \& Herwig, U. (2016). Neural correlates of mindful self-awareness in mindfulness meditators and meditation-naive subjects revisited. Biological Psychology, 119, 21-30. https://doi.org/10.1016/j.biopsycho.2016.06.010

Mahone, M. C., Travis, F., Gevirtz, R., \& Hubbard, D. (2018). fMRI during transcendental meditation practice. Brain and Cognition, 123, 30-33. https://doi.org/10.1016/j.bandc.2018.02.011

Medvedev, O. N., Siegert, R. J., Feng, X. J., Billington, D. R., Jang, J. Y., \& Krägeloh, C. U. (2016). Measuring trait mindfulness: How to improve the precision of the Mindful Attention Awareness Scale using a Rasch model. Mindfulness, 7(2), 384-395.

Medvedev, O. N., Siegert, R. J., Kersten, P., \& Krägeloh, C. U. (2017). Improving the precision of the Five Facet Mindfulness Questionnaire using a Rasch approach. Mindfulness, 8(4), 995-1008.

Mennes, M., Kelly, C., Zuo, X. N., Di Martino, A., Biswal, B. B., Castellanos, F. X., \& Milham, M. P. (2010). Inter-individual differences in resting-state functional connectivity predict task-induced BOLD activity. NeuroImage, 50(4), 1690-1701. https://doi.org/ 10.1016/j.neuroimage.2010.01.002

Modestino, E. J. (2016). Neurophenomenology of an altered atate of consciousness: An fMRI case study. Explore, 12(2), 128-135. https://doi.org/10.1016/j.explore.2015.12.004

Mooneyham, B. W., Mrazek, M. D., Mrazek, A. J., Mrazek, K. L., Ihm, E. D., \& Schooler, J. W. (2017). An integrated assessment of changes in brain structure and function of the insula resulting from an intensive mindfulness-based intervention. Journal 
of Cognitive Enhancement, 1, 327-336. https://doi.org/10.1007/ s41465-017-0034-3

Nash, J. D., \& Newberg, A. (2013). Toward a unifying taxonomy and definition for meditation. Frontiers in Psychology, 4, 806. https:// doi.org/10.3389/fpsyg.2013.00806

Panda, R., Bharath, R. D., Upadhyay, N., Mangalore, S., Chennu, S., \& Rao, S. L. (2016). Temporal dynamics of the default mode network characterize meditation-induced alterations in consciousness. Frontiers in Human Neuroscience, 10, 372. https://doi.org/ 10.3389/fnhum.2016.00372

Park, T., Reilly-Spong, M., \& Gross, C. R. (2013). Mindfulness: A systematic review of instruments to measure an emergent patientreported outcome (PRO). Quality of Life Research, 22(10), 26392659. https://doi.org/10.1007/s11136-013-0395-8

Parker, D. B., \& Razlighi, Q. R. (2019). Task-evoked negative BOLD response and functional connectivity in the default mode network are representative of two overlapping but separate neurophysiological processes. Scientific Reports, 9(1), 14473. https://doi.org/ 10.1038/s41598-019-50483-8

Pascoe, M. C., Thompson, D. R., Jenkins, Z. M., \& Ski, C. F. (2017). Mindfulness mediates the physiological markers of stress: Systematic review and meta-analysis. Journal of Psychiatric Research, 95, 156-178. https://doi.org/10.1016/j.jpsychires.2017.08.004

Sangharakshita. (2012). Know your mind. Windhorse Publications Ltd.

Sato, J. R., Kozasa, E. H., Wallace, B. A., \& Amaro, E., Jr. (2017). Neuroimaging data from a single participant before and after a meditation retreat: A proof of concept study. Journal of Cognitive Enhancement, 1, 235-241. https://doi.org/10.1007/ s41465-017-0025-4

Scheibner, H. J., Bogler, C., Gleich, T., Haynes, J. D., \& Bermpohl, F. (2017). Internal and external attention and the default mode network. NeuroImage, 148, 381-389. https://doi.org/10.1016/j. neuroimage.2017.01.044

Sevinc, G., Holzel, B. K., Hashmi, J., Greenberg, J., McCallister, A., Treadway, M., Schneider, M. L., Dusek, J. A., Carmody, J., \& Lazar, S. W. (2018). Common and dissociable neural activity after mindfulness-based stress reduction and relaxation response programs. Psychosomatic Medicine, 80(5), 439-451. https://doi.org/ 10.1097/PSY.0000000000000590

Shao, R., Keuper, K., Geng, X., \& Lee, T. M. (2016). Pons to posterior cingulate functional projections predict affective processing changes in the elderly following eight weeks of meditation training. eBioMedicine, 10, 236-248. https://doi.org/10.1016/j.ebiom. 2016.06.018

Simon, R., Pihlsgård, J., Berglind, U., Söderfeldt, B., \& Engström, M. (2017). Mantra meditation suppression of default mode beyond an active task: A pilot study. Journal of Cognitive Enhancement, 1(2), 219-227. https://doi.org/10.1007/s41465-017-0028-1

Smith, S. M., Fox, P. T., Miller, K. L., Glahn, D. C., Fox, P. M., Mackay, C. E., Filippini, N., Watkins, K. E., Toro, R., Laird, A. R., \& Beckmann, C. F. (2009). Correspondence of the brain's functional architecture during activation and rest. Proceedings of the National Academy of Sciences of the United States of America, 106(31), 13040-13045. https://doi.org/10.1073/pnas.0905267106

Steyer, R., Mayer, A., Geiser, C., \& Cole, D. A. (2015). A theory of states and traits - revised. Annual Review of Clinical Psychology, 11, 71-98. https://doi.org/10.1146/annurev-clinp sy-032813-153719

Subhuti. (2015). Mind in harmony: A guide to the psychology of buddhist ethics. Windhorse Publications.

Tang, Y. Y., Tang, Y., Tang, R., \& Lewis-Peacock, J. A. (2017). Brief mental training reorganizes large-scale brain networks. Frontiers in Systems Neuroscience, 11, 6. https://doi.org/10.3389/fnsys. 2017.00006

Taren, A. A., Gianaros, P. J., Greco, C. M., Lindsay, E. K., Fairgrieve, A., Brown, K. W., Rosen, R. K., Ferris, J. L., Julson, E., Marsland,
A. L., \& Creswell, J. D. (2017). Mindfulness meditation training and executive control network resting state functional connectivity: A randomized controlled trial. Psychosomatic Medicine, 79(6), 674-683. https://doi.org/10.1097/PSY.0000000000000466

Thornton, M. A., Weaverdyck, M. E., \& Tamir, D. I. (2019). The brain represents people as the mental states they habitually experience. Nature Communications, 10(1), 2291. https://doi.org/10.1038/ s41467-019-10309-7

Tomasino, B., \& Fabbro, F. (2016). Increases in the right dorsolateral prefrontal cortex and decreases the rostral prefrontal cortex activation after- 8 weeks of focused attention based mindfulness meditation. Brain and Cognition, 102, 46-54. https://doi.org/10. 1016/j.bandc.2015.12.004

Truong, Q. C., Krägeloh, C. U., Siegert, R. J., Landon, J., \& Medvedev, O. N. (2020). Applying generalizability theory to differentiate between trait and state in the Five Facet Mindfulness Questionnaire (FFMQ). Mindfulness, 11(4), 953-963.

Turner, B. O., Paul, E. J., Miller, M. B., \& Barbey, A. K. (2018). Small sample sizes reduce the replicability of task-based fMRI studies. Communications Biology, 1, 62. https://doi.org/10.1038/ s42003-018-0073-Z

Van Dam, N. T., van Vugt, M. K., Vago, D. R., Schmalzl, L., Saron, C. D., Olendzki, A., Meissner, T., Lazar, S. W., Kerr, C. E., Gorchov, J., Fox, K. C. R., Field, B. A., Britton, W. B., Brefczynski-Lewis, J. A., \& Meyer, D. E. (2018). Mind the hype: A critical evaluation and prescriptive agenda for research on mindfulness and meditation. Perspectives on Psychological Science, 13(1), 36-61. https:// doi.org/10.1177/1745691617709589

Winter, U., LeVan, P., Borghardt, T. L., Akin, B., Wittmann, M., Leyens, Y., \& Schmidt, S. (2019). Content-free awareness: EEGfcMRI correlates of consciousness as such in an expert meditator. Frontiers in Psychology, 10, 3064. https://doi.org/10.3389/fpsyg. 2019.03064

Wittmann, M., Otten, S., Schotz, E., Sarikaya, A., Lehnen, H., Jo, H. G., Kohls, N., Schmidt, S., \& Meissner, K. (2014). Subjective expansion of extended time-spans in experienced meditators. Frontiers in Psychology, 5, 1586. https://doi.org/10.3389/fpsyg. 2014.01586

Xiao, Q., Zhao, X. R., Bi, G. L., Wu, L. S., Zhang, H. J., Liu, R. X., Zhong, J. M., Wu, S. Y., Zeng, Y., Cui, L. Q., Chen, Y. M., Wu, K. H., \& Chen, Z. F. (2019). Alterations of regional homogeneity and functional connectivity following short-term mindfulness meditation in healthy volunteers. Frontiers in Human Neuroscience, 13. https://doi.org/10.3389/fnhum.2019.00376

Xie, Y. (2013). Population heterogeneity and causal inference. Proceedings of the National Academy of Sciences of the United States of America, 110(16), 6262-6268. https://doi.org/10.1073/pnas. 1303102110

Yang, C. C., Barros-Loscertales, A., Pinazo, D., Ventura-Campos, N., Borchardt, V., Bustamante, J. C., Rodriguez-Pujadas, A., FuentesClaramonte, P., Balaguer, R., Avila, C., \& Walter, M. (2016). State and training effects of mindfulness meditation on brain networks reflect neuronal mechanisms of its antidepressant effect. Neural Plasticity, 2016, 9504642. https://doi.org/10.1155/2016/9504642

Young, K. S., van der Velden, A. M., Craske, M. G., Pallesen, K. J., Fjorback, L., Roepstorff, A., \& Parsons, C. E. (2018). The impact of mindfulness-based interventions on brain activity: A systematic review of functional magnetic resonance imaging studies. Neuroscience \& Biobehavioral Reviews, 84, 424-433. https://doi.org/ 10.1016/j.neubiorev.2017.08.003

Publisher's Note Springer Nature remains neutral with regard to jurisdictional claims in published maps and institutional affiliations. 